\title{
Produção de pimentão cultivado com pó de pedra e esterco em região semiárida
}

Production pepper cultivated with stone dust and manure in semi-arid region

Producción de chile cultivado con polvo de piedra y estiércol en una región semiárida

Recebido: 08/05/2020 | Revisado: 11/05/2020 | Aceito: 13/05/2020 | Publicado: 24/05/2020

\section{Katiana Luma Ferreira Mendes}

ORCID: https://orcid.org/0000-0003-2532-3634

Instituto Federal de Educação Ciência e Tecnologia da Paraíba, Brasil

E-mail: katianaluma20@gmail.com

Hugo Vieira

ORCID: https://orcid.org/0000-0002-9583-8409

Instituto Federal de Educação Ciência e Tecnologia da Paraíba, Brasil

E-mail: hugoprofessorifpb@yahoo.com

Ednaldo Barbosa Pereira Junior

ORCID: https://orcid.org/0000-0003-0098-3206

Instituto Federal de Educação Ciência e Tecnologia da Paraíba, Brasil

E-mail: ebprj2@hotmail.com

Joserlan Nonato Moreira

ORCID: https://orcid.org/0000-0002-2290-7119

Instituto Federal de Educação Ciência e Tecnologia da Paraíba, Brasil

E-mail: joserlan.moreira@ifpb.edu.br

Katiana de Sousa Vale

ORCID: https://orcid.org/0000-0002-7476-0198

Instituto Federal de Educação Ciência e Tecnologia da Paraíba, Brasil

E-mail: katianasv.eco@gmail.com

Clarice Ribeiro Alves Caiana

ORCID: https://orcid.org/0000-0002-5374-1617

Universidade Federal de Campina Grande, Brasil

E-mail: clariceribeirocaiana@gmail.com 
Francisco das Chagas Bezerra Neto

ORCID: https://orcid.org/0000-0001-6232-4383

Universidade Federal de Campina Grande, Brasil

E-mail: chagasneto237@gmail.com

Aline Carla de Medeiros

ORCID: https://orcid.org/0000-0002-0161-3541

Universidade Federal de Campina Grande, Brasil

E-mail: alinecarla.edu@gmail.com

Patrício Borges Maracajá

ORCID: https://orcid.org/0000-0003-4812-0389

Universidade Federal da Paraíba, Brasil

E-mail: patriciomaracaja@gmail.com

\section{Resumo}

A pesquisa foi realizada objetivando-se verificar o efeito do pó de rocha e esterco bovino como fontes naturais para adubação e nutrição da cultura do pimentão (Capsicum annuum L. cv. All Big). O experimento foi conduzido no viveiro de mudas do Instituto Federal de Educação Ciência e Tecnologia da Paraíba - IFPB, Campus Sousa, Unidade São Gonçalo durante o período de setembro de 2014 a agosto de 2015. O delineamento experimental utilizado foi em blocos ao acaso (DBC) com 10 tratamentos e 4 repetições, totalizando 40 unidades experimentais. Os tratamentos foram os seguintes: $\mathrm{T}_{1}=$ testemunha $(\mathrm{Solo}), \mathrm{T}_{2}=$ Solo + Esterco + Pó de Rocha (1:1:1) ; $\mathrm{T}_{3}=$ Solo + Esterco + Pó de Rocha (2:1:1); $\mathrm{T}_{4}$ = Solo + Esterco + Pó de Rocha $(2: 2: 1) ; \mathrm{T}_{5}=$ Solo + Esterco + Pó de Rocha $(2: 2: 2) ; \mathrm{T}_{6}=$ Solo + Esterco + Pó de Rocha (3:1:1) $; \mathrm{T}_{7}=$ Solo + Esterco + Pó de Rocha (3:2:1) ; $\mathrm{T}_{8}=$ Solo + Esterco + Pó de Rocha (3:2:2); $\mathrm{T}_{9}=$ Solo + Esterco + Pó de Rocha (3:3:2) ; e $\mathrm{T}_{10}=$ Solo + Esterco + Pó de Rocha (3:3:3). Foram avaliados, altura de plantas, massa fresca da parte aérea, massa fresca da raiz, massa seca da parte aérea, massa seca de raiz, comprimento do fruto, diâmetro do fruto, massa fresca de fruto, massa seca de fruto, produção total e produção comercial. Os tratamentos testados influenciaram de forma significativa nas variáveis: matéria seca e fresca da raiz, parte aérea fresca e seca, comprimento do fruto (segunda colheita) e massa seca do fruto (segunda colheita). A associação do pó de rocha com o esterco bovino, subprodutos naturais, rico em nutrientes essenciais ao desenvolvimento e produção das plantas, apresenta-se como alternativa em potencial para fins de uso na agricultura. $\mathrm{O}$ tratamento $T_{8}$ proporcionou maior produção comercial com frutos no padrão comercial. 
Palavras-chave: Solo; Pimentão; Agroecologia.

\begin{abstract}
The research was carried out aiming to verify the effect of rock powder and bovine manure as natural sources for fertilization and nutrition of the pepper culture (Capsicum annuum L. cv. All Big). The experiment was carried out in the seedling nursery of the Federal Institute of Education Science and Technology of Paraíba - IFPB, Campus Sousa, São Gonçalo Unit during the period from September 2014 to August 2015. The experimental design used was in randomized blocks (DBC) with 10 treatments and 4 repetitions, totaling 40 experimental units. The treatments were as follows: $\mathrm{T} 1=$ control (soil), $\mathrm{T} 2=$ soil + manure + rock powder (1: 1: 1); T3 = Soil + Dung + Rock Dust (2: 1: 1); T4 = Soil + Dung + Rock Dust (2: 2: 1); T5 $=$ Soil + Dung + Rock Dust (2: 2: 2); T6 = Soil + Dung + Rock Dust (3: 1: 1); T7 = Soil + Dung + Rock Dust (3: 2: 1); T8 = Soil + Dung + Rock Dust (3: 2: 2); T9 = Soil + Dung + Rock Dust (3: 3: 2); and T10 = Soil + Dung + Rock Dust (3: 3: 3). Plant height, fresh shoot weight, fresh root weight, dry shoot weight, dry root weight, fruit length, fruit diameter, fresh fruit weight, dry fruit weight, total production and commercial production. The treatments tested significantly influenced the variables: dry and fresh root material, fresh and dry aerial part, fruit length (second harvest) and dry fruit mass (second harvest). The association of rock powder with bovine manure, natural by-products, rich in nutrients essential to the development and production of plants, presents itself as a potential alternative for use in agriculture. The T8 treatment provided greater commercial production with fruits in the commercial standard.
\end{abstract}

Keywords: Solo; Bell pepper; Agroecology.

\title{
Resumen
}

La investigación se realizó con el objetivo de verificar el efecto del polvo de roca y el estiércol bovino como fuentes naturales para la fertilización y nutrición del cultivo de pimiento (Capsicum annuum L. cv. All Big). El experimento se llevó a cabo en el vivero de plántulas del Instituto Federal de Educación, Ciencia y Tecnología de Paraíba - IFPB, Campus Sousa, Unidad de São Gonçalo durante el período de septiembre de 2014 a agosto de 2015. El diseño experimental utilizado fue en bloques aleatorizados (DBC ) con 10 tratamientos y 4 repeticiones, totalizando 40 unidades experimentales. Los tratamientos fueron los siguientes: $\mathrm{T} 1=$ control $($ suelo), $\mathrm{T} 2=$ suelo + estiércol + polvo de roca (1: 1: 1); T3 $=$ Suelo + Estiércol + Polvo de roca $(2: 1: 1) ;$ T4 = Suelo + Estiércol + Polvo de roca (2: 2: 1); 
T5 = Suelo + Estiércol + Polvo de roca (2: 2: 2); T6 = Suelo + Estiércol + Polvo de roca (3: 1: 1); T7 = Suelo + Estiércol + Polvo de roca (3: 2: 1); T8 = Suelo + Estiércol + Polvo de roca (3: 2: 2); T9 = Suelo + Estiércol + Polvo de roca (3: 3: 2); y T10 = Suelo + Estiércol + Polvo de roca (3: 3: 3). Altura de la planta, peso del brote fresco, peso de la raíz fresca, peso del brote seco, peso de la raíz seca, longitud del fruto, diámetro del fruto, peso del fruto fresco, peso del fruto seco, producción total y producción comercial Los tratamientos probados influyeron significativamente en las variables: material de raíz seca y fresca, parte aérea fresca y seca, longitud del fruto (segunda cosecha) y peso del fruto seco (segunda cosecha). La asociación del polvo de roca con el estiércol bovino, subproductos naturales, ricos en nutrientes esenciales para el desarrollo y la producción de plantas, se presenta como una alternativa potencial para su uso en la agricultura. El tratamiento con T8 proporcionó una mayor producción comercial con frutas en el estándar comercial.

Palabras clave: Solo; Pimienta; Agroecología.

\section{Introdução}

O pimentão (Capsicum annuum L.) é uma planta arbustiva, originária do continente americano, com sistema radicular pivotante e profundo, atingindo até $120 \mathrm{~cm}$ de profundidade. Seus frutos possuem alto teor de vitamina $\mathrm{C}$ e são utilizados na fabricação de condimentos, conservas, molhos, etc (Carvalho et al., 2011).

Do ponto de vista econômico, está entre as dez hortaliças mais importantes do mercado brasileiro por ser uma cultura de rápido retorno rentável aos investimentos, visto o curto período para o início da produção explorada por pequenos e médios horticultores (Marcussi \& Bôas, 2003).

É uma cultura bastante exigente no que diz respeito às características químicas e físicas do meio de cultivo, respondendo muito bem à adubação orgânica, e excelentes produtividades podem ser obtidas por meio da associação de adubos orgânicos e minerais (Alves et al., 2009), no entanto, informações técnicas relativas ao seu desempenho produtivo em sistemas orgânicos, ainda são escassas.

Araújo et al. (2007), avaliando a produção de pimentão adubado com esterco bovino e biofertilizante, concluíram que o biofertilizante bovino, aplicado de forma isolada ou associado com material orgânico, pode ser utilizado como alternativa para fertilização nãoconvencional no pimentão. Resultados semelhantes também foram observados por Alves et al. (2009). 
Estudando o efeito do biofertilizante suíno na nutrição e produtividade do pimentão colorido, Sediyama et al. (2014), contatam que a aplicação via solo permite melhorar o estado nutricional e produtivo das cultivares de pimentão, em sistema de cultivo orgânico a campo, com reflexos positivos nos teores foliares de nutrientes e nas produtividades comercial, precoce e de frutos extras.

A utilização de resíduos na atividade agrícola é interessante do ponto de vista econômico por proporcionar aumento de produtividade das plantas e reduzir o custo com fertilizantes, além da deposição segura desses materiais no ambiente (Figueiredo \& Tanamati, 2010).

O aproveitamento das rochas, como fontes restituidoras de nutrientes para as plantas, recuperadora e renovadora do solo, pode configurar uma tecnologia alternativa capaz de auxiliar na redução do uso de produtos químicos, especialmente aqueles incorporados em formas altamente solúveis (Pinheiro \& Barreto, 1996; Theodoro, 2000).

A remineralização do solo, através do uso do pó de rocha, favorece o rejuvenescimento de solos pobres em nutrientes e lixiviados, promovendo o equilíbrio da fertilidade e a produtividade sustentável. O desenvolvimento e a aplicação desse manejo nos solos de forma integrada, implica na redução e possível dependência de fertilizantes minerais, assegurando práticas ecológicas e seguras (Brandão, 2013).

Por não ser um fertilizante industrializado, o pó de rocha possui um baixo valor agregado de custo, tornando-se assim, um insumo acessível tanto para o pequeno e grande produtor rural (D'andréa, 2003). O Brasil, apresenta uma enorme geodiversidade e que, portanto, pode viabilizar o uso de diferentes tipos de rochas, em diferentes regiões, para alcançar padrões de diversidades compatíveis com as necessidades regionais e ainda facilitar mecanismos de desenvolvimento local (Theodoro, 2000).

Pesquisas tem apontado aspectos relevantes do potencial do uso do pó de rocha no âmbito social (Theodoro, 2000), ambiental (Altieri, 1987; D'andréa, 2003; Empresa de Assistência Técnica e Extensão Rural do Rio Grande do Sul [EMATER/RS], 2009;) e nutricional (Gomes et al., 2000; Empresa Brasileira de Pesquisa Agropecuária [EMBRAPA], 2004; Melamed et al., 2007; Martins, 2010; Brandão, 2013). Porém, ainda são insipientes os trabalhos que buscam estudar proporções e associações dessa matéria prima nas culturas.

É nesse contexto a pesquisa busca oferecer novos conhecimentos no que concerne a novas opções por meio do pó de rocha associado ao esterco bovino como fonte alternativas em substituição a adubação química no processo da cadeia produtiva do pimentão. 


\section{Metodologia}

As pesquisas são realizadas com a finalidade de alcançar novos saberes na sociedade como preconizam Pereira et al. (2018). No presente estudo, a pesquisa foi realizada no viveiro de mudas do IFPB, Campus Sousa, Unidade São Gonçalo (6 $6^{\circ} 50^{\prime} 33 " S ; 38^{\circ} 17^{\prime} 54^{\prime \prime}$ W e 264m), durante o período de setembro de 2014 a agosto de 2015.

O delineamento experimental foi em blocos ao acaso, com 10 tratamentos e quatro repetições, totalizando 40 unidades experimentais. Os tratamentos resultaram da combinação de solo, esterco e pó de rocha, nas proporções: $\mathrm{T}_{1}($ Solo $)=$ testemunha; $\mathrm{T}_{2}(1: 1: 1)=$ Solo + Esterco + Pó de Rocha; $\mathrm{T}_{3}(2: 1: 1)=$ Solo + Esterco + Pó de Rocha; $\mathrm{T}_{4}$ (2:2:1) = Solo + Esterco + Pó de Rocha; $T_{5}$ (2:2:2) = Solo + Esterco + Pó de Rocha; T 6 (3:1:1) = Solo + Esterco + Pó de Rocha; $\mathrm{T}_{7}$ (3:2:1) = Solo + Esterco + Pó de Rocha; $\mathrm{T}_{8}$ (3:2:2) = Solo + Esterco + Pó de Rocha; $\mathrm{T}_{9}(3: 3: 2)=$ Solo + Esterco + Pó de Rocha e $\mathrm{T}_{10}$ (3:3:3) = Solo + Esterco + Pó de Rocha.

As amostras dos materiais foram analisadas no Laboratório de Análise de Solo, Água e Planta (LASAP) do IFPB Campus Sousa, com os seguintes resultados: solo proveniente de um Neossolo Flúvico ( $\mathrm{pH}=7,40 ; \mathrm{P}=828 \mathrm{mg} \mathrm{dm}^{-3} ; \mathrm{K}=0,93 \mathrm{cmol}_{\mathrm{c}} \mathrm{dm}^{-3} ; \mathrm{Na}=1,3 \mathrm{cmol}_{\mathrm{c}} \mathrm{dm}^{-3}$; $\mathrm{Ca}=7,0 \mathrm{cmol}_{\mathrm{c}} \mathrm{dm}^{-3} ; \mathrm{Mg}=2,5 \mathrm{cmol}_{\mathrm{c}} \mathrm{dm}^{-3}, \mathrm{Al}=0,0 \mathrm{cmol}_{\mathrm{c}} \mathrm{dm}^{-3} ; \mathrm{H}+\mathrm{Al}=0,0 \mathrm{cmol}_{\mathrm{c}} \mathrm{dm}^{-3} ; \mathrm{M} . \mathrm{O}=$ 29,98 $\mathrm{g} \mathrm{kg}^{-1}$ ), esterco bovino ( $\left.\mathrm{N}=17,5 \mathrm{~g} \mathrm{~kg}^{-1} ; \mathrm{P}=15,93 \mathrm{~g} \mathrm{~kg}^{-1} ; \mathrm{K}=11,28 \mathrm{~g} \mathrm{~kg}^{-1}\right)$ e pó de rocha $\left(\mathrm{pH}=8,7 ; \mathrm{P}=1729 \mathrm{mg} \mathrm{dm}{ }^{-3} ; \mathrm{K}=0,26 \mathrm{cmol}_{\mathrm{c}} \mathrm{dm}^{-3}, \mathrm{Na}=0,18 \mathrm{cmol}_{\mathrm{c}} \mathrm{dm}^{-3} ; \mathrm{Ca}=3,4\right.$ $\mathrm{cmol}_{\mathrm{c}} \mathrm{dm}^{-3} ; \mathrm{Mg}=0,0 \mathrm{cmol}_{\mathrm{c}} \mathrm{dm}^{-3} ; \mathrm{Al}=0,0 \mathrm{cmol}_{\mathrm{c}} \mathrm{dm}^{-3} ; \mathrm{H}+\mathrm{Al}=0,0 \mathrm{cmol}_{\mathrm{c}} \mathrm{dm}^{-3} ; \mathrm{M} . \mathrm{O}=2,70 \mathrm{~g}$ $\left.\mathrm{kg}^{-1}\right)$.

Após o preparo dos substratos (tratamentos), os depósitos de poliestireno com capacidade de 5,0 L foram preenchidos manualmente e conduzidos ao viveiro, permanecendo sete dias sob irrigações diárias antes de receberem as mudas.

As mudas de pimentão (Cultivar All Big), foram produzidas em bandejas de poliestireno de 128 células. O transplantio foi realizado aos 35 dias após a semeadura (DAS), sendo três mudas por vaso. Aos 19 dias após o transplantio (DAT) foi realizado o desbaste, deixando-se as duas plântulas mais vigorosas.

As irrigações foram realizadas em dois períodos diariamente, fornecendo um volume de água suficiente para elevar a umidade do substrato próximo à capacidade de campo. As plantas invasoras foram eliminadas manualmente, assim que as mesmas surgiam.

Aos 71 e 115 DAS foram avaliadas as seguintes características: altura de plantas - AP [obtido pela distância entre o nível do solo e a parte apical da planta com o auxilio de uma 
régua graduada em centímetros $(\mathrm{cm})$ ], massa fresca da parte aérea - MFPA [obtida pela separação da raiz aos 115 DAS, através de um corte na região do colo e determinada com o auxílio de balança digital expressa em gramas (g)], massa fresca da raiz - MFR [obtida pela separação da parte aérea aos 115 DAS, através de um corte na região do colo e determinada com o auxílio de balança digital, expressa em gramas (g)], massa seca da parte aérea - MSPA [obtida pela separação da raiz aos 115 DAS, através de um corte na região do colo, acondicionadas em sacos de papel, etiquetadas e secadas em estufa a $65^{\circ} \mathrm{C}$, com circulação forçada de ar até peso constante, expressa em gramas (g)], massa seca de raiz - MSR [obtida pela separação da parte aérea aos 115 DAS, através de um corte na região do colo, acondicionadas em sacos de papel, etiquetadas e secadas em estufa a $65^{\circ} \mathrm{C}$, com circulação forçada de ar até peso constante, expressa em gramas (g)], comprimento do fruto - CF [obtido pela distância vertical entre os extremos do fruto com o auxílio de um paquímetro digital, expresso em milímetros (mm)], diâmetro do fruto - DF [obtido pela distância horizontal entre os extremos do fruto com o auxílio de um paquímetro digital, expresso em milímetros $(\mathrm{mm})]$, massa fresca de fruto - MFF [obtido pela soma total dos frutos na área útil secadas em estufa a $65^{\circ} \mathrm{C}$, com circulação forçada de ar até peso constante, expressa em gramas (g)], massa seca de fruto - MSF [obtido pela soma dos frutos da área útil produção total - PT (obtida pelas somas das produções dos tratamentos nas duas colheitas, expressa em gramas (g)] e produção comercial - PC [obtida pela seleção comercial de valores do frutos, expressa em gramas (g) (CEAGESP [Companhia de Entrepostos e Armazéns Gerais de São Paulo], 2010).

Os resultados foram submetidos à análise de variância (teste F) aos níveis de 0,01 e 0,05 de significância, e as médias (fontes) comparadas pelo teste de Tukey, a 5\% de probabilidade, utilizando-se do software estatístico SISVAR (Ferreira, 2014).

\section{Resultados e Discussão}

Houve diferença significativa para massa fresca da parte aérea e massa seca da parte aérea, e massa fresca de raízes e massa seca de raízes aos 71 e 115 DAS (P < 0,05). Não foi constatada diferença significativa para altura de plantas (Tabela 1), mesmo assim, percebe-se que os tratamentos $\mathrm{T}_{9}$ e $\mathrm{T}_{10}$, expressaram valores médios acima do tratamento testemunha; provavelmente esses valores tenham sido influenciados pelas maiores combinações de solo, esterco e pó de rocha. Coelho et al. (2013) utilizando Tropstrato®, Tropstrato® + areia, e Tropstrato ${ }^{\circledR}+$ composto orgânico, obtiveram excelentes resultados para a altura de plantas em mudas na variedade híbrido vermelho AF 7086. Sediyama et al. (2014), estudando a 
nutrição de plantas de pimentão adubadas com biofertilizante suíno foi observado que as maiores alturas de plantas foram obtidas na maior dose de fertilizante. Almeida et al. (2018) testando fontes orgânicas, dispõe que o efeito satisfatório no milho adubado com esterco ovino.

Para massa fresca e seca da parte aérea diferenças significativas foram observadas $(\mathrm{P}<$ $0,05)$, sendo os tratamentos $\mathrm{T}_{2}$ e $\mathrm{T}_{9}$ superiores aos demais (Tabela 1 ).

Tabela 1: Valores médios para altura de plantas (AP), massa fresca da parte aérea (MFPA), massa seca da parte aérea (MSPA), massa fresca de raiz (MFR) e massa seca de raiz (MSR) do pimentão sob efeito do pó de rocha como fonte natural na adubação.

\begin{tabular}{|c|c|c|c|c|c|c|}
\hline \multirow{3}{*}{ Tratamentos/Proporções } & \multirow{2}{*}{\multicolumn{2}{|c|}{$\begin{array}{c}\text { AP }(\mathbf{c m}) \\
\text { DAS }\end{array}$}} & \multirow{3}{*}{ MFPA (g) } & \multirow{3}{*}{ MSPA (g) } & \multirow{3}{*}{$\begin{array}{c}\text { MFR } \\
(\mathbf{g})\end{array}$} & \multirow{3}{*}{$\begin{array}{c}\text { MSR } \\
(\mathbf{g})\end{array}$} \\
\hline & & & & & & \\
\hline & 71 & 115 & & & & \\
\hline T1 (Solo) & $41,63 a^{*}$ & $49,00 \mathrm{a}$ & $8,56 \mathrm{bc}$ & $2,09 \mathrm{c}$ & $12,42 \mathrm{ab}$ & $5,80 \mathrm{ab}$ \\
\hline T2 (1:1:1) & $50,73 \mathrm{a}$ & $51,98 \mathrm{a}$ & $116,22 \mathrm{a}$ & $33,97 \mathrm{ab}$ & $26,80 \mathrm{a}$ & $10,06^{\mathrm{a}}$ \\
\hline T3 (2:1:1) & $40,27 \mathrm{a}$ & $42,68 \mathrm{a}$ & $79,09 b c$ & $24,57 b c$ & $16,76 a b c$ & $6,77 \mathrm{ab}$ \\
\hline T4 (2:2:1) & $47,75 a$ & $48,88 \mathrm{a}$ & $98,69 \mathrm{ab}$ & $30,30 \mathrm{abc}$ & $15,82 b c$ & $6,72 \mathrm{ab}$ \\
\hline T5 (2:2:2) & $39,23 a$ & $47,25 \mathrm{a}$ & $68,48 b c$ & $29,82 \mathrm{abc}$ & $16,8 \mathrm{abc}$ & $8,93 \mathrm{ab}$ \\
\hline T6 (3:1:1) & $42,48 \mathrm{a}$ & $53,68 \mathrm{a}$ & $60,67 \mathrm{c}$ & $29,30 \mathrm{abc}$ & $11,50 \mathrm{bc}$ & $6,18 \mathrm{ab}$ \\
\hline T7 (3:2:1) & $39,67 a$ & $47,45 a$ & $77,26 \mathrm{bc}$ & $31,06 \mathrm{abc}$ & $11,59 b c$ & $5,45 b$ \\
\hline T8 (3:2:2) & $37,42 a$ & $52,00 \mathrm{a}$ & $64,56 c$ & $30,15 \mathrm{abc}$ & $9,90 \mathrm{c}$ & $5,32 b$ \\
\hline T9 (3:3:2) & $52,82 \mathrm{a}$ & $58,86 a$ & $83,26 a b c$ & $36,59^{\mathrm{a}}$ & $16,74 \mathrm{abc}$ & $8,06 \mathrm{ab}$ \\
\hline T10 (3:3:3) & $58,28 \mathrm{a}$ & $60,63 \mathrm{a}$ & $68,91 \mathrm{bc}$ & $34,51 \mathrm{ab}$ & $11,86 \mathrm{bc}$ & $6,64 \mathrm{ab}$ \\
\hline C.V. $(\%)$ & 12,21 & 16,40 & 17,37 & 14,95 & 8,26 & 7,23 \\
\hline
\end{tabular}

*Médias seguidas pela mesma letra na coluna não diferem estatisticamente entre si pelo teste de Tukey ao nível de 5\% de probabilidade. Fonte: Autoria Própria (2020).

Para as variáveis massa fresca e seca de raiz, os tratamentos $T_{2}$ e $T_{1}$, expressaram os melhores resultados (Tabela 1). Tal comportamento pode ser evidenciado pelo alto valor do potássio analisado no substrato. Estes resultados foram inferiores aos encontrados por Fontes et al. (2005), que verificaram acúmulo de matéria seca da parte aérea de 368,1 g, aos 224 DAT na cultura do pimentão cultivado em solo.

Acredita-se que a fertilidade do substrato inferiu positivamente no desempenho dessas variáveis podendo ser constatado esse acúmulo pelo alto teor de cálcio, potássio e fósforo analisado no substrato. Negreiros (1995) e Silva et al. (2010) estudando a cultura do pimentão, expõe que os valores da matéria fresca da parte aérea foram altos, decrescendo rapidamente, com a idade das plantas. Segundo Williams (1946), esse decréscimo é atribuído, em parte, ao incremento gradativo de tecidos não fotossintetizantes, à medida que as plantas se desenvolvem. Barbosa e Silva et al. (2010), analisando o crescimento de pimentão em diferentes arranjos espaciais, mostra o aumento da massa fresca com o aumento da idade das 
plantas. Para massas secas, constataram que o aumento do espaçamento reduziu a competição entre as plantas, favorecendo a expressão de maiores teores.

Lopes et al. (2011) verificaram acúmulo máximo de biomassa de 684,96 g na cultura do tomate. Minami (1995) relata que quanto maior a quantidade de raízes, maior a quantidade de nutrientes disponíveis no intervalo entre o transplante e a formação de novas raízes. De acordo com Faquin (1994) o potássio é responsável pela ativação enzimática, tem função de osmorregulação, na fotossíntese e no transporte de carboidratos.

Para comprimento e diâmetro de frutos aos 71 e 115 DAS, não foram observadas diferenças significativas entre os tratamentos (Tabela 2). No entanto, o tratamento $\mathrm{T}_{8}$ se sobressaiu dos demais, seguido pelo $\mathrm{T}_{10}$. Os melhores resultados para comprimento de frutos foram expressos pelos tratamentos $\mathrm{T}_{1}, \mathrm{~T}_{2}$ e $\mathrm{T}_{8}$ aos 115 DAS. Os valores de comprimento e diâmetro observados nessa pesquisa, incluem os frutos no padrão comercial tipo 'extra', frutos graúdos (CEAGESP 2010).

Tabela 2: Valores médios de comprimento $(\mathrm{CF})$ e diâmetro (DF) de frutos, massa fresca (MFF) e massa seca (MSF) de frutos de pimentão aos 71 e 105 DAS sob efeito do pó de rocha como fonte natural na adubação.

\begin{tabular}{|c|c|c|c|c|c|c|c|c|}
\hline \multirow[t]{3}{*}{ Tratamentos/Proporções } & \multicolumn{2}{|c|}{$\begin{array}{l}\text { Comprimento } \\
\text { de fruto }(\mathrm{mm})\end{array}$} & \multicolumn{2}{|c|}{$\begin{array}{l}\text { Diâmetro de } \\
\text { fruto }(\mathrm{mm})\end{array}$} & \multicolumn{2}{|c|}{$\begin{array}{l}\text { Massa fresca } \\
\text { de fruto }(\mathrm{g})\end{array}$} & $\begin{array}{c}\text { Massa } \\
\text { seca de } \\
\text { fruto }(g)\end{array}$ & $\begin{array}{c}\text { Massa } \\
\text { seca de } \\
\text { fruto }(\mathrm{g})\end{array}$ \\
\hline & & & & & & & \multicolumn{2}{|c|}{ DAS } \\
\hline & 71 & 115 & 71 & 115 & 71 & 115 & 71 & 115 \\
\hline T1 (Solo) & $61,23 a^{*}$ & $51,09 \mathrm{a}$ & $44,90 \mathrm{a}$ & $40,64 a$ & $42,17 \mathrm{a}$ & $27,77 \mathrm{a}$ & $12,56 \mathrm{a}$ & $11,45 \mathrm{ab}$ \\
\hline T2 $(1: 1: 1)$ & $65,15^{\mathrm{a}}$ & $48,75 \mathrm{ab}$ & $44,88 \mathrm{a}$ & $38,00 \mathrm{a}$ & $42,95 \mathrm{a}$ & $23,25 \mathrm{a}$ & $11,56 \mathrm{a}$ & $10,42 \mathrm{ab}$ \\
\hline T3 (2:1:1) & $60,65^{\mathrm{a}}$ & $21,74 \mathrm{c}$ & $44,72 \mathrm{a}$ & $17,09 \mathrm{a}$ & $41,10 \mathrm{a}$ & $24,06 \mathrm{a}$ & $14,43 \mathrm{a}$ & $6,42 b$ \\
\hline T4 (2:2:1) & $63,42^{\mathrm{a}}$ & $32,42 \mathrm{abc}$ & $47,55 \mathrm{a}$ & $36,58 \mathrm{a}$ & $43,01 \mathrm{a}$ & $32,74 \mathrm{a}$ & $18,17 \mathrm{a}$ & $12,80 \mathrm{ab}$ \\
\hline T5 (2:2:2) & $62,66^{\mathrm{a}}$ & $30,52 \mathrm{bc}$ & $48,39 \mathrm{a}$ & $17,12 \mathrm{a}$ & $44,54 \mathrm{a}$ & $20,57 \mathrm{a}$ & $17,18 \mathrm{a}$ & $8,15 b$ \\
\hline T6 (3:1:1) & $68,19^{a}$ & $33,57 \mathrm{bc}$ & $44,40 \mathrm{a}$ & $18,28 \mathrm{a}$ & $42,49 \mathrm{a}$ & $22,88 \mathrm{a}$ & $14,03 \mathrm{a}$ & $10,97 \mathrm{ab}$ \\
\hline T7 (3:2:1) & $63,32^{\mathrm{a}}$ & $30,01 b c$ & $46,85 a$ & $20,21 \mathrm{a}$ & $46,81 \mathrm{a}$ & $21,98 \mathrm{a}$ & $11,48 \mathrm{a}$ & $11,80 \mathrm{ab}$ \\
\hline T8 (3:2:2) & $68,95^{\mathrm{a}}$ & $43,09 \mathrm{ab}$ & $42,53 \mathrm{a}$ & $22,97 \mathrm{a}$ & $41,22 a$ & $33,74 \mathrm{a}$ & $13,45 \mathrm{a}$ & $15,84 \mathrm{abc}$ \\
\hline T9 (3:3:2) & $59,46^{\mathrm{a}}$ & $37,60 \mathrm{abc}$ & $48,49 a$ & $23,89 a$ & $49,34 \mathrm{a}$ & $34,38 \mathrm{a}$ & $13,08 \mathrm{a}$ & $13,59 \mathrm{ab}$ \\
\hline T10 (3:3:3) & $65,36^{\mathrm{a}}$ & $35,99 \mathrm{abc}$ & $49,27 \mathrm{a}$ & $41,44 \mathrm{a}$ & $43,42 \mathrm{a}$ & $30,52 \mathrm{a}$ & $9,32 \mathrm{a}$ & $21,99^{\mathrm{a}}$ \\
\hline C.V. (\%) & 14,79 & 12,86 & 15,03 & $26,76 a$ & 26,63 & 26,83 & 28,69 & 21,28 \\
\hline
\end{tabular}

*Médias seguidas pela mesma letra na coluna não diferem estatisticamente entre si pelo teste de Tukey ao nível de 5\% de probabilidade. Fonte: Autoria Própria (2020).

Não houve diferenças significativas entre os tratamentos para massa fresca de frutos aos 71 e 115 DAS e massa seca aos 71 DAS (Tabela 2). Mesmo assim, pode-se observar diminuição do peso dos frutos ao longo do tempo. Para massa seca, o tratamento $\mathrm{T}_{10}$ seguido $\operatorname{dos} \mathrm{T}_{9}, \mathrm{~T}_{4}, \mathrm{~T}_{7}$ e $\mathrm{T}_{2}$ não diferiram estatisticamente entre si.

Os valores médios de produção total e comercial do pimentão não expressaram efeitos diferenciados entre os tratamentos (Tabela 3). Na produção total a combinação 3:3:3 de solo, esterco e pó de rocha $\left(\mathrm{T}_{10}\right)$, se sobressaiu dos demais. Para produção comercial, a combinação 
3:2:2, tratamento $T_{8}$, se demonstrou mais eficiente. Araújo et al. (2007) também trabalharam com a cultivar All Big e obtiveram, na presença de biofertilizante aplicado no solo, produção média de 410, $6 \mathrm{~g}$ de frutos por planta e produtividade de 8,3 $\mathrm{t} \mathrm{ha}^{-1}$ de frutos comerciais em função das doses de esterco bovino. Melo et al. (2000), avaliando composto orgânico associado a doses de adubação mineral em campo, obtiveram o número máximo de frutos comerciais estimado com a aplicação de 84,03 $\mathrm{t} \mathrm{ha}^{-1}$ de composto orgânico também associado à maior dose de adubação mineral. Este fato também foi contatado por Roe et al. (1997), os quais não observaram aumento na produção comercial de frutos de pimentão com a aplicação de comporto orgânico + fertilizante NPK. Segundo esses autores, a adição do fertilizante mineral pode mascarar os efeitos benéficos da adição do material orgânico sobre a produção do pimentão.

Oliveira et al. (2004) observaram aumento linear de produção com a elevação das concentrações de urina de vaca, tanto na presença, como na ausência da adubação mineral. Na presença da adubação mineral, ocorreu um incremento na ordem de $54 \mathrm{~g}$ de frutos/planta a cada percentual de urina de vaca acrescido na solução, com uma produção de $982 \mathrm{~g}$ de frutos na concentração de 5\%, enquanto que na sua ausência, esse incremento foi na ordem de $23 \mathrm{~g}$ de frutos/planta, com a produção máxima de $428 \mathrm{~g}$ de frutos na concentração de $5 \%$ de urina de vaca. Sediyama et al. (2014), ao avaliarem efeitos de biofertilizante de suíno na produtividade de pimentão colorido, não observaram efeito de doses produtividade de frutos das classes especial e primeira classe, cujo valor médio foi de $1,02 \mathrm{t} \mathrm{ha}^{-1}$ para a classe primeira e para a especial observou-se maior produtividade para cv. Rubia com 4,47 $\mathrm{t} \mathrm{ha}^{-1} \mathrm{e}$ 'Amanda' com 3,16 t ha' ${ }^{-1}$.

Tabela 3: Valores médios de produção total (PT) e comercial (PC) de frutos de pimentão sob efeito do pó de rocha como fonte natural na adubação.

\begin{tabular}{ccc}
\hline Tratamentos/Proporções & Produção total (g) & Produção comercial (g) \\
\hline T1 (Solo) & $17,00 \mathrm{a}^{*}$ & $14,00 \mathrm{a}$ \\
T2 (1:1:1) & $15,50 \mathrm{a}$ & $11,50^{\mathrm{a}}$ \\
T3 (2:1:1) & $16,00 \mathrm{a}$ & $11,50^{\mathrm{a}}$ \\
T4 (2:2:1) & $19,50 \mathrm{a}$ & $14,00 \mathrm{a}$ \\
T5 (2:2:2) & $19,00 \mathrm{a}$ & $1,00 \mathrm{a}$ \\
T6 (3:1:1) & $19,00 \mathrm{a}$ & $10,50^{\mathrm{a}}$ \\
T7 (3:2:1) & $19,00 \mathrm{a}$ & $20,00 \mathrm{a}$ \\
T8 (3:2:2) & $20,50 \mathrm{a}$ & $12,50^{\mathrm{a}}$ \\
T9 (3:3:2) & $19,00 \mathrm{a}$ & $11,50^{\mathrm{a}}$ \\
\hline T10 (3:3:3) & $24,00 \mathrm{a}$ & 26,55 \\
\hline
\end{tabular}

*Médias seguidas pela mesma letra na coluna não diferem estatisticamente entre si pelo teste de Tukey ao nível de 5\% de probabilidade. Fonte: Autoria Própria (2020). 


\section{Considerações Finais}

As proporções de solo, esterco e pó de rocha, influenciaram de forma significativa as variáveis: matéria seca e fresca da raiz, parte aérea fresca e seca, comprimento do fruto e massa seca do fruto aos 115 dias após a semeadura.

O pó de rocha associado ao esterco bovino, subprodutos naturais, rico em nutrientes essenciais ao desenvolvimento e produção das plantas, apresentam-se como alternativa em potencial para fins de uso na agricultura.

A utilização de solo, esterco e brita nas proporções de 3-3-3 e 3-2-2 proporciona pimentões com maiores produções total (24 g) e comercial (20 g), respectivamente.

\section{Referências}

Almeida, RS, Vieira, H, Paiva, RSA \& Gurjão, KCO. (2018). Avaliação de diferentes fontes de adubação orgânica em cultivo de milho Zea mays crioulo. Revista de Agroecologia no Semiárido, [S.1.], 1(2): 10-7, jan. ISSN 2595-0045. Acesso em 20 março 2020, em https://periodicos.ifpb.edu.br/index.php/ras/article/view/1778.

Araújo, EN, Oliveira, AP, Cavalcante, LF, Pereira, WE, Brito, NM, Neves, CML, \& SILVA, ÉÉ. (2007). Produção do pimentão adubado com esterco bovino e biofertilizante. Revista Brasileira de Engenharia Agrícola e Ambiental, 11(5): 466-70.

Alves, GS, Salva, JA, Nascimento, JAM, Cavalcante, LF \& Dantas, TAG. (2009). Estado nutricional do pimentão cultivado em solo tratado com diferentes tipos de fertilizantes. Acta Scientiarum. Agronomy, 31(4): 661-65.

Altieri, MA. (1987). Agroecology: the scientific basis of alternative agriculture. Boulder: West View Press. 227 p.

Barbosa e Silva, PI, Negreiros, MZ, Moura, KKCF, Freitas, FCL, Nunes, GHS, Lima e Silva, PS \& Grangeiro, LC. (2010). Crescimento de pimentão em diferentes arranjos espaciais. Pesquisa Agropecuária Brasileira, 45(2): 132-39. 
Brandão, JAV. (2013). Pó de rocha como fonte de nutrientes no contexto da agroecologia. 2013. 83 f. Dissertação (Mestrado). Universidade Federal de São Carlos, Araras.

Carvalho, JA, Rezende, FC, Aquino, RF, Freitas, WA \& Oliveira, EC. (2011). Análise produtiva e econômica do pimentão-vermelho, irrigado com diferentes lâminas, cultivado em ambiente protegido. Revista Brasileira de Engenharia Agrícola e Ambiental, 15(6): 569-74.

CEAGESP. (2010). Norma de classificação do pimentão para o programa brasileiro para a melhoria dos padrões comerciais e embalagens de hortigranjeiros.

Coelho, JLS, Silva, RM, Baima, WDS, Gonçalves, HRO, Santos Neto, FC \& Aguiar, AVM. (2013). Diferentes substratos na produção de mudas de pimentão. Agropecuária Científica no Semiárido, 9(2): 01-14.

Correia, LG. (1984). Colheita, rendimento, classificação de pimentão e pimenta. Informe Agropecuário, Belo Horizonte: EPAMIG 10: 70-72.

D’andréa, P. A. (2003). Rochagem no Brasil: Regulamentação.

EMBRAPA. (2004). Pó de rocha será nova fonte de potássio para agricultura.

EMATER/RS. (2009). Pó de basalto usado como fertilizante surpreende produtores de mudas no Vale do Caí. Nota Técnica.

Figueiredo, PG \& Tanamati, FY. Adubação orgânica e contaminação ambiental. (2010). Revista Verde de Agroecologia e Desenvolvimento Sustentável, 5(1): 1-4.

Fontes, PCR, Dias, EN \& Silva, DJH. (2005). Dinâmica do crescimento, distribuição de matéria seca e produção de pimentão em ambiente protegido. Horticultura Brasileira, Brasília, 23(1): 94-9.

Faquin, V. (1994). Nutrição mineral de plantas. Lavras: UFLA, FAEPE, 227 p. 
Ferreira, DF. (2014). SISVAR - Sistema de Análise de Variância para Dados Balanceados. Lavras: UFLA, 19 p.

Gomes, MAF, Souza, MD, Boeira, RC \& Toledo, LG. (2000). Nutrientes vegetais no meio ambiente: ciclos bioquímicos, fertilizantes e corretivos. Jaguariúna: Embrapa Meio Ambiente, 50 p.

Lopes, WAR, Dias, EN \& Silva, DJH. (2011). Análise do crescimento de tomate 'SM16 `cultivado sob diferentes coberturas de solo. Horticultura Brasileira, Brasília, 29(4): 55461.

Marcussi, FFN \& Bôas, RLV. (2003). Teores de macronutrientes no desenvolvimento da planta de pimentão sob fertirrigação. Irriga, 8(2): 120-31.

Martins, ES, Oliveira, CG, Resende, AV \& Matos, MSF. (2010). “Agrominerais - Rochas silicáticas como fontes minerais alternativas de potássio para a agricultura". In: Luz, AB \& Lins, FF. (Eds.) Rochas e Minerais Industriais: Usos e especificações, 2 ed., cap. 9, Rio de Janeiro, Brasil, Centro de Tecnologia Mineral.

Melamed, R, Gaspar, JC \& Miekeley, N. (2007). Pó-de-rocha como fertilizante alternativo para sistemas de produção sustentáveis em solos tropicais. Parte de tese (Doutorado). Series estudos e documentos. SED-72, CETEM/MCT.

Melo, SC, Pereira, HS \& Vitti, GC. (2000). Efeito de fertilizantes orgânicos na nutrição e produção do pimentão. Horticultura Brasileira, 18(1): 200-20.

Minami, K. (1995). Produção de mudas de alta qualidade em horticultura. São Paulo: T.A. Queiroz.

Negreiros, MZ. (1995). Crescimento, partição de matéria seca, produção e acúmulo de macronutrientes de plantas de pimentão (Capsi cumannum L.) em cultivo podado e com cobertura morta. (Tese doutorado) - UFV, Viçosa. $187 \mathrm{f}$. 
Oliveira, PA, Paes, RA, Souza, AP, Dornelas, CSM, Silva, RA. (2004). Produção de pimentão em função da concentração de urina de vaca aplicada via foliar e da adubação com NPK. Agropecuária Técnica, 25(1): 37-43.

Pereira, AS, Shitsuka, DM, Parreira, FJ \& Shitsuka, R. (2018). Metodologia da pesquisa científica. [e-book]. Santa Maria. Ed. UAB/NTE/UFSM. Disponível em: https://repositorio.ufsm.br/bitstream/handle/1/15824/Lic_Computacao_MetodologiaPesquisa-Cientifica.pdf?sequence $=1$.

Pinheiro, S \& Barreto, SB. (1996). “MB-4” Agricultura Sustentável, Trofobiose e Biofertilizantes. Canoas: Fundação Juquira Candiru: MIBASA. 273 p.

Roe, NE, Stoffella, PJ \& Graetz, D. (1997). Composts from various municipal solid waste feedstocks affect vegetable crops. II. Growth, yields, and fruit quality. Journal American Society Horticultural Science, 122(1): 433-7.

Sediyama, MAN, Santos, MR, Vidigal, SM, Pinto, CLO \& Jacob, LL. (2014). Nutrição e produtividade de plantas de pimentão colorido, adubadas com biofertilizante de suíno. Revista Brasileira de Engenharia Agrícola e Ambiental. 18(6): 588-94.

Silva, PIB, Gonçalves, HRO, Santos Neto, FC \& Aguiar, AVM. (2010). Crescimento de pimentão em diferentes arranjos espaciais. Pesquisa Agropecuária Brasileira, Brasília, 45(2): 132- 39.

Theodoro, SHA. (2000). Fertilização da Terra pela Terra: Uma Alternativa de Sustentabilidade para o Pequeno Produtor Rural. (Tese de doutorado) - UFB, Brasília, 231 f.

Williams, RF. (1946). The physiology of plant growth with special reference to the concept of net assimilations rate. Ann. Bot, 10(1): 41-72. 
Research, Society and Development, v. 9, n. 7, e487974360, 2020

(CC BY 4.0) | ISSN 2525-3409 | DOI: http://dx.doi.org/10.33448/rsd-v9i.4360

Porcentagem de contribuição de cada autor no manuscrito

Katiana Luma Ferreira Mendes - 12\%

Hugo Vieira - 11\%

Ednaldo Barbosa Pereira Junior - 11\%

Joserlan Nonato Moreira $-11 \%$

Katiana de Sousa Vale $-11 \%$

Clarice Ribeiro Alves Caiana - $11 \%$

Francisco das Chagas Bezerra Neto - $11 \%$

Aline Carla de Medeiros - 11\%

Patrício Borges Maracajá - 11\% 